Soheila Asadpour Behzadi, Enayatollah Sheikhhosseini*, Sayed Ali Ahmadi, Dadkhoda Ghazanfari and Mohammadreza Akhgar

\title{
Synthesis and characterization of novel biological tetracoumarin derivatives bearing ether moieties
}

https://doi.org/10.1515/hc-2020-0009

Received April 12, 2019; accepted January 10, 2020.

Abstract: A series of novel tetracoumarin derivatives (3a-f) were prepared using the reaction of ether functionalized dibenzaldehyde with 4-hydroxycoumarin in the presence of sodium acetate. The structure of compounds was validated by IR, NMR, and CHN analyzes. Antimicrobial (antibacterial and antifungal) activity was studied on the basis of the minimum bactericidal concentration, minimum inhibitory concentration and inhibitory zone diameter. Favorable biological activity was found in compound $\mathbf{3 f}$.

Keywords: tetracoumarin, 4-hydroxycoumarin, aqueous media, ethylene ether spacer, biological activity

\section{Introduction}

Coumarins are a vital category of common oxygen heterocyclic composites. The extensive scope of biological activities pertaining to coumarins and their therapeutic impact against various pathologies have received significant attention in developing several drugs [1-5]. Furthermore, medicinal chemists have been fascinated by the stability and solubility of these compounds which has led to their medicinal applicability $[6,7]$.

Coumarin derivatives consist of numerous biological activities e.g. anticoagulant, anticonvulsant, antihypertensive, anti-inflammatory, anti-adipogenic, neuroprotective, antioxidant and anti-hyperglycemic traits, in addition to extensive cytotoxic impacts towards bacteria,

\footnotetext{
*Corresponding author: Enayatollah Sheikhhosseini, Department of Chemistry, Kerman Branch, Islamic Azad University, Kerman, Iran, email: sheikhhosseiny@gmail.com

Soheila Asadpour Behzadi, Sayed Ali Ahmadi, Dadkhoda Ghazanfari and Mohammadreza Akhgar, Department of Chemistry, Kerman Branch, Islamic Azad University, Kerman, Iran
}

tubercular cells, cancer cells, fungi, viruses [8], phytoalexin, hypnotic, anti-helminthic, insecticidal and HIV protease constraints $[9,10]$. Several naturally generated derivatives of coumarin are used suitably as flexible building components to stereo selectively construct natural products, namely alkaloids [11,12], macrolides [13], terpenoinds [14-16] and pheromones [17]. The widespread use of the coumarin groups include designing fluorescent chemosensors [18,19], tagged polymers [20], solar cells [21], cellular imaging tools [22], and extensive utilization for the purpose of synthesizing laser dyes [22,23].

The flexible medical and biological biscoumarins activities, bridged substituted dimers of 4-hydroxycoumarin and its derivatives, have attracted significant interest in the past few years leading to the simplicity of aromatic ring fine tuning via various substituents resulting in numerous chemical analogues with biological activities e.g. anticancer, anti-coagulants, antibacterial, antiinflammatory, and antioxidant behavior [24-29]. A number of biscoumarins have also been determined as urease inhibitors [30], as well as in the prevention and treatment of thrombosis [31].

Moreover, biscoumarins-Lanthanum III composites are reported to display efficient cytotoxic behavior [32]. Warfarin sodium, one such derivative, is utilized in treating numerous cancers and enhances rates of survival within patients suffering from different types of cancer [33]. Dicoumaral-taxol composites have proven to exhibit synergetic hindrance of embryos and sea urchin cell division [34,35]. By determining the significance of composites, scholars are interested in synthesizing derivatives of biscoumarin. It is believed that as the number of coumarins increases in a compound, the biological activity also increases. However, there are few reports with four coumarin skeletons in their molecular structures [36-40].

The biological importance of coumarin derivatives led to the belief that combining four coumarin skeletons into an individual composite by synthetic methodology whilst preparing and characterizing relevant derivatives can entail biological behavior. For this paper we design 
and document new tetra 4-hydroxycoumarin derivatives' synthesis which contain ether groups.

\section{Result and discussion}

Upon our previous works using ethylene glycol-based dialdehyde derivatives [41,42], efficient synthesis of tetracoumarins was achieved by condensation of ethylene glycol-based aromatic dialdehydes and 4-hydroxycoumarin in the presence of sodium acetate in methanol (Scheme 1).

The results related to the reaction of different ethylene glycol-based dialdehyde with 4-hydroxycoumarin were summarized in Table 1.

As is clear from Table 1, the reaction of ethylene glycol-based salicylaldehyde (1b-f) with 4-hydroxycoumarin (Table 1, entries 2-6) to give tetra 4-hydroxycoumarins (3b-f) were shown in favorable yield.

The reaction between ethylene glycol-based naphthaldehyde, with 4-hydroxycoumarin (Table 1, entries 1) affords tetra 4-hydroxycoumarins (3a) in moderate to good yields. Nevertheless the replacement (electron-donating and -withdrawing) of the aromatic dialdehydes, the products were obtained in favorable yields.

Under the same conditions, when dialdehyde 1d-f were allowed to react with 4- hydroxycoumarin. Surprisingly, when the products were isolated, ${ }^{1} \mathrm{H}$ NMR data did not show the formation of tetra coumarins in enolic form (Table 1, entries 4-6). While hydroxyl groups are expected to be apparent in the ${ }^{1} \mathrm{H}$ NMR spectrum of these compounds, the ${ }^{1} \mathrm{H}$ NMR spectra showed xanthene derivatives were obtained, formed from the cyclization of biscoumarins. The ${ }^{1} \mathrm{H}$ NMR spectrum of $\mathbf{3 b}$ indicated the present protons of at $\delta: 4.06(\mathrm{~m}), 4.27(\mathrm{~m}), 5.64(\mathrm{~s})$ and 12.60-12.61 (m) belonging to the protons of $\mathrm{O}-\mathrm{CH}_{2}$ (ethylene glycol), bridge $\mathrm{CH}$ and $\mathrm{OH}$ (enol form), respectively. Also, the structure of compound $\mathbf{3 b}$ was further confirmed by ${ }^{13} \mathrm{C}$ NMR spectrum and the peaks were observed at $\delta$ : 32.9 and 65.8, $67.3 \mathrm{ppm}$ for the $\mathrm{O}-\mathrm{CH}_{2}$ and bridged $\mathrm{CH}$ accordingly. The ${ }^{1} \mathrm{H}$ NMR of $\mathbf{3 f}$ showed a singlet and two triplet signals at $\delta: 3.00,3.31$ and 3.83 ppm respectively for the three methylene protons along with a singlet signal at $\delta: 6.19 \mathrm{ppm}$ for the $\mathrm{CH}$-aliphatic hydrogen. ${ }^{13} \mathrm{C}$ NMR spectrum of this product showed three signals at $\delta: 67.8,69.1$, 69.9 for the methylene carbons and a signal at $33.6 \mathrm{ppm}$ for the $\mathrm{CH}$-aliphatic carbon as well as the carbonyl carbon at $164.9 \mathrm{ppm}$. In general, all the structures were analysed by FT-IR, ${ }^{1} \mathrm{H}$ NMR and ${ }^{13} \mathrm{C}$ NMR. The spectral data supported the structures of the compounds 3a-f.

On the basis of the reported synthesis of biscoumarin in the literature [43,44], our proposed mechanism (Scheme 2) shows sodium acetate as the base catalyst for the improved yield of the Knoevenagel condensation reaction of 4-hydroxycomarin 2 with diaromatic aldehyde 1 to produce 3 by elimination of a water molecule. Eventually, the second molecule of 4-hydroxycoumarin 2 will be added to the double bond of intermediate 5 and the desired product 3 is produced that could then cyclise to product 6.


Scheme 1 Synthesis of tetracoumarin derivatives containing ether groups. 
Minimum inhibitory concentration (MIC) and minimum bactericidal concentration (MBC) determination

The microorganism's inoculums were assembled from 12 hour broth cultures whilst suspensions were modified to 0.5 McFarland standard turbidity. The heterocyclic compounds' MIC towards microbial strains was ascertained on the basis of micro well dilution technique. The minimum concentration hindrance growth was considered as MIC for the compounds [45]. The test bacteria MIC was ascertained via triple assays. For the purpose of validating MICs and establishing MBCs, $10 \mu \mathrm{L}$ of broth was

Table 1 Bisarylidene tetracoumarin derivatives containing ether groups obtained by the condensation of diaromatic aldehydes with 4-hydroxycoumarin.




Table 1 (Continued)
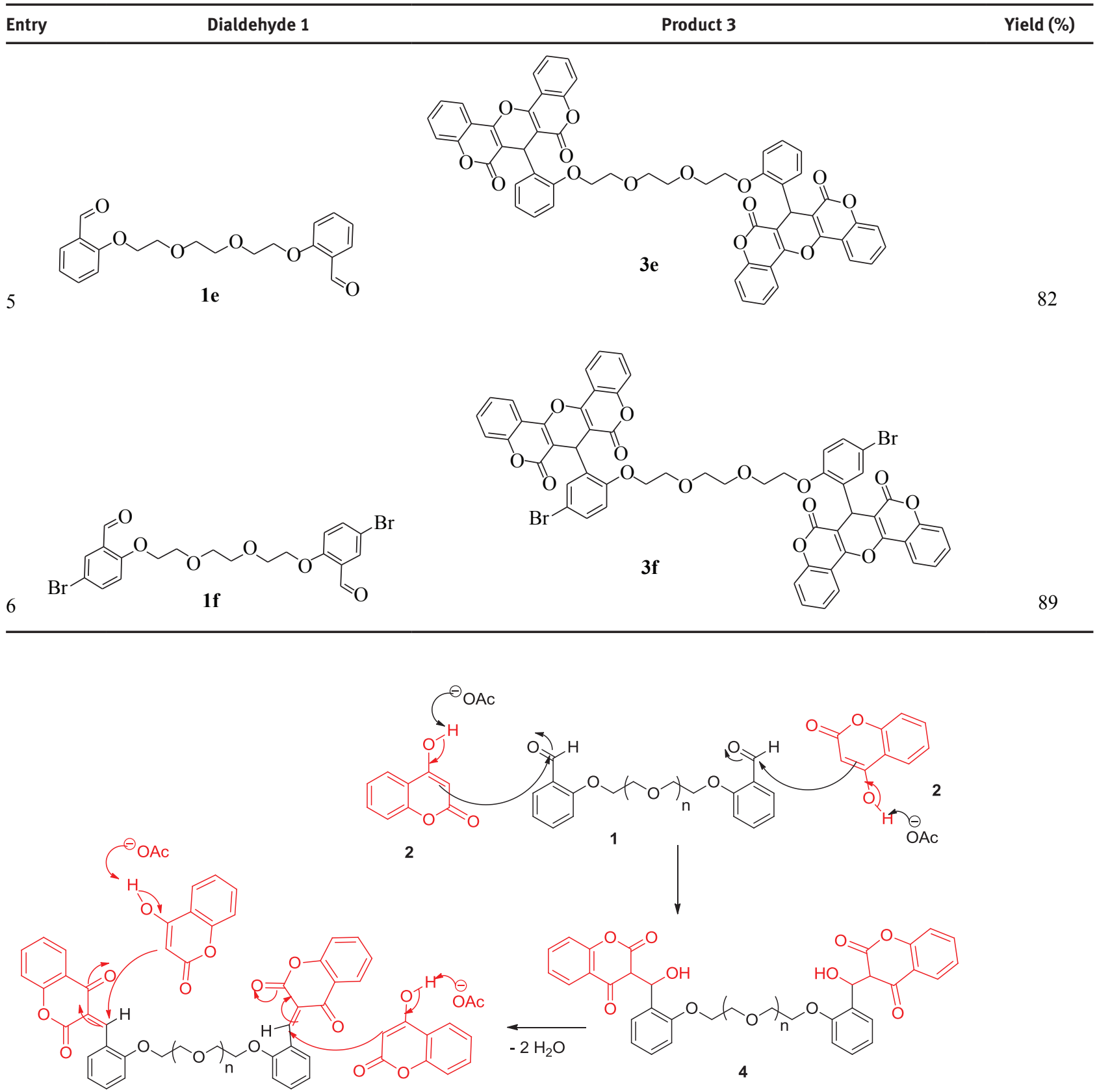

5

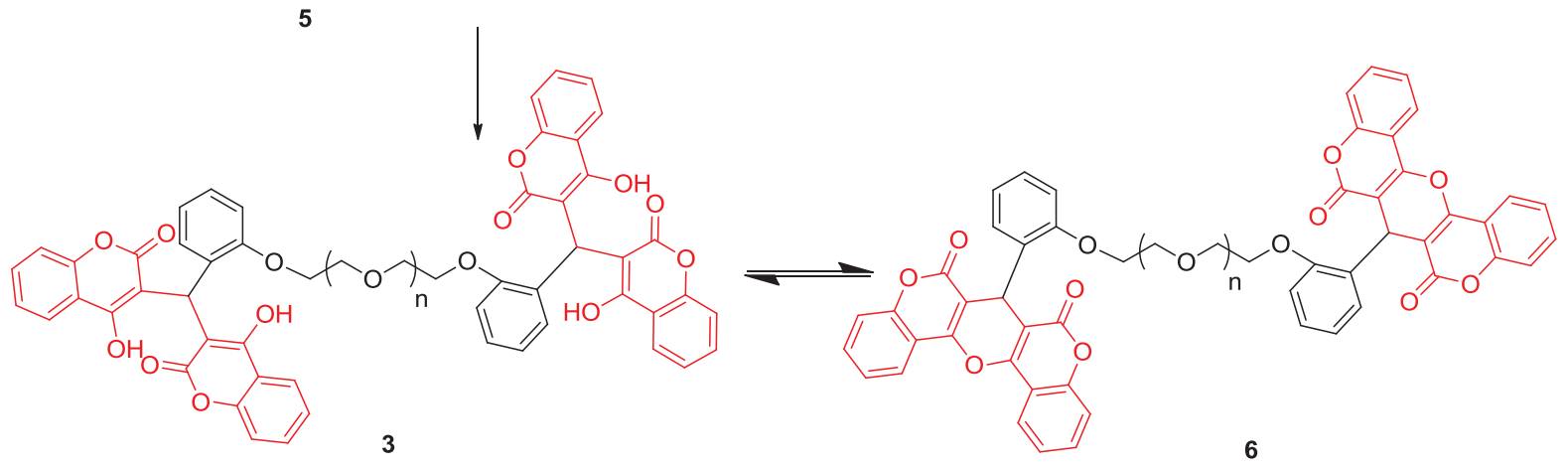

Scheme 2 Proposed mechanism for the synthesis of tetracoumarins. 
extracted from every well and subjected to inoculation using the Muller-Hinton agar i.e. MHA plates. These plates were subjected to incubation for a period of 24 hours under $37^{\circ} \mathrm{C}$ temperature whilst being observed to determine the existence or absence of growth. The least concentration inhibiting evident organism growth was considered as MBC [46]. The processes were replicated three times.

Antibacterial possibilities of the compounds were experiments in terms of bacterial strains and Candida albicans. Table 2 presents the findings. Confirmation of the antibacterial behavior data determined that some of these compounds had good bactericidal properties against indicator strains. It is shown that $\mathbf{3 c}$ did not have any antimicrobial activity against $A$. baumannii. Streptomyces fradiae exhibited resistance to $\mathbf{3 a}$ compound. According to Table 2, 3f showed high antifungal activity and furthermore the MIC and MFC are the same as Terbinafine. All the synthesized compounds had antibacterial activity but some were bacteria were resistant. For example, $A$. baumannii and $S$. fradiae were resistant to $3 \mathrm{c}$ and 3a compounds respectively. Resistance to chemical agents can have different causes The inability of the chemical to penetrate the bacterial cell wall either due to hydrophobicity, having pumps actively efflux out of the cell or generally excreting the substance out of the cell can be reasons for ineffectiveness. These mechanisms are important in medicine as it can contribute to bacterial antimicrobial agents resistance.

Biological activity of 4-hydroxycoumarin in Table 2 show that wherever synthesized tetracomarins do not have biological properties, 4-hydroxycoumarin is not biological but the amount of biological activity of these products relative to 4-hydroxycoumarin has no meaningful trend.

In conclusion, we have developed a precipitation response of ethylene glycol-based dialdehyde with 4-hydroxycoumarin. This synthesis occurs efficiently in the presence of $\mathrm{NaOAc}$, without an additional assisting catalyst in methanol to achieve tetracoumarine derivatives in good yield. Additionally, these products showed biological activity.

\section{Experimental}

\section{Materials and instruments}

The implemented substances were commercially available and purified. Melting points were ascertained using an

Table 2 Antibacterial activity of the synthesized compounds against some microorganisms.

\begin{tabular}{|c|c|c|c|c|c|c|c|c|c|c|}
\hline \multicolumn{3}{|c|}{ Microorganism } & \multicolumn{6}{|c|}{ Products } & \multicolumn{2}{|c|}{ 4-hydroxy coumarin } \\
\hline & & & $3 a$ & $3 b$ & $3 c$ & $3 d$ & $3 e$ & $3 f$ & & $\mathbf{a} / \mathbf{b}$ \\
\hline \multirow{9}{*}{  } & P. aeruginosa & IZD & 12.07 & 9.82 & 11.48 & 9.74 & 12.11 & 13.94 & 9.37 & 24.65 \\
\hline & & MIC & 256 & 1024 & 512 & 512 & 256 & 64 & 2048 & 0.5 \\
\hline & & $M B C$ & 512 & 2048 & 1024 & 1024 & 256 & 128 & 4096 & 0.5 \\
\hline & A. baumannii & IZD & 11.96 & 0 & 0 & 0 & 12.44 & 12.76 & 0 & 17.76 \\
\hline & & MIC & 512 & 0 & 0 & 0 & 128 & 65 & 0 & 32 \\
\hline & & $M B C$ & 512 & 0 & 0 & 0 & 256 & 64 & 0 & 32 \\
\hline & S. dysenteriae & IZD & 13.45 & 0 & 12.17 & 8.67 & 13.52 & 14.72 & 0 & 20.54 \\
\hline & & MIC & 512 & 0 & 256 & 1024 & 64 & 64 & 0 & 0.126 \\
\hline & & $\mathrm{MBC}$ & 1024 & 0 & 512 & 2048 & 128 & 128 & 0 & 0.254 \\
\hline \multirow{9}{*}{ 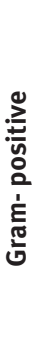 } & E. faecalis & IZD & 14.64 & 10.79 & 13.42 & 11.31 & 13.67 & 14.76 & 10.62 & 22.01 \\
\hline & & MIC & 128 & 512 & 128 & 512 & 64 & 64 & 512 & 1 \\
\hline & & $M B C$ & 256 & 1024 & 128 & 512 & 128 & 128 & 1024 & 2 \\
\hline & S. fradiae & IZD & 0 & 0 & 10.94 & 0 & 13.71 & 9.85 & 0 & 20.96 \\
\hline & & MIC & 0 & 0 & 512 & 0 & 128 & 128 & 0 & 16 \\
\hline & & $M B C$ & 0 & 0 & 512 & 0 & 256 & 256 & 0 & 32 \\
\hline & S. aureus & IZD & 8.52 & 12.56 & 13.47 & 13.47 & 10.68 & 9.92 & 11.98 & 21.27 \\
\hline & & MIC & 256 & 512 & 64 & 256 & 128 & 64 & 1024 & 2 \\
\hline & & $\mathrm{MBC}$ & 512 & 1024 & 128 & 512 & 128 & 128 & 1024 & 2 \\
\hline \multirow{3}{*}{ 品 } & C. albicans & IZD & 8.41 & 8.47 & 8.43 & 8.43 & 8.12 & 8.26 & 8.14 & 14.26 \\
\hline & & MIC & 1024 & 2048 & 512 & 1024 & 512 & 256 & 2048 & 256 \\
\hline & & MFC & 2048 & 4096 & 1024 & 2048 & 512 & 512 & 4096 & 512 \\
\hline
\end{tabular}

a: Gentamicin for bacteria; b: Terbinafine for fungi

IZD Values reported as mm; MIC, MBC and MFC Values reported as $\mu \mathrm{g} / \mathrm{mL}$ 
Electrothermal 9100 device and subjected to being uncorrected. An ABB FT-IR FTLA 2000 spectrometer was used to acquire IR spectra. ${ }^{1} \mathrm{H}$ NMR and ${ }^{13} \mathrm{C}$ NMR spectra were executed using a Bruker spectrometer modified at $400 \mathrm{MHz}$ for ${ }^{1} \mathrm{H}$ NMR and $100 \mathrm{MHz}$ for ${ }^{13} \mathrm{C}$ NMR. $\mathrm{CDCl}_{3}$ and DMSO- $\mathrm{d}_{6}$ were implemented as solvents. C, $\mathrm{H}, \mathrm{N}$ and $\mathrm{S}$ elemental evaluations were conducted using a Heraeus CHN-S-ORapid analyzer.

\section{General process for the preparation of ditosylates}

$40 \mathrm{mmol}$ of 4-tolylsulfonyl chloride, $40 \mathrm{~mL}$ of DCM and 21 mmol of associated ethylene glycol was stirred for $15 \mathrm{~min}$ at a temperature of $0-5^{\circ} \mathrm{C}$. Subsequently, $46 \mathrm{mmol}$ of triethyl amine was added in drop wise manner. TLC was used to monitor the progress of the reaction. The remaining tosylchloride was extracted by the addition of triethyl amine in powder form (11.5 mmol) and it was intensely ground for a period of 10 minutes. Upon completion, the resulting solid product was filtered and water was used to stir for 10 minutes. The resulting crude tosylate was adequately refined.

\section{Common process to synthesize dialdehyde derivatives (1a-f)}

$4 \mathrm{mmol}$ of polyethylene glycol ditosylate, $8 \mathrm{mmol}$ of salicylaldehyde derivatives, and $20 \mathrm{mmol}$ of $\mathrm{K}_{2} \mathrm{CO}_{3}$ were included in $40 \mathrm{~mL}$ of acetonitrile solvent. The concoction was refluxed for $24 \mathrm{~h}$ and monitored by TLC until total conversion of the starting materials. The mixture was initially filtered prior to the filtrate being distilled then diluted with acetonitrile $(50 \mathrm{~mL})$ and washed using $\mathrm{NaOH} 10 \%$ $(3 \times 20 \mathrm{~mL})$. The resulting product was concentrated via solvent evaporation with the use of a rotary evaporator, which did not require any extensive refinement.

\section{Common process to synthesize tetracoumarins (3a-f)}

Finally, in order to synthesize tetra tetracoumarin containing ethylene ether spacers; $1 \mathrm{mmol}$ of diaromatic aldehyde containing ether groups (1a-f), 4 mmol of 4-hydroxycoumarin and $1 \mathrm{mmol}$ of acetate sodium in methanol $(10 \mathrm{~mL})$ was mixed and refluxed for $16-20 \mathrm{~h}$ at $80{ }^{\circ} \mathrm{C}$. Upon completion of reaction (supervised by TLC) and after cooling, the solid substances were extracted from the solution. After this time, the reaction concoction was subjected to cooling, and the solid product was collected and recrystallized from $\mathrm{EtOH}$ and $\mathrm{MeOH}$ to afford the corresponding tetra tetracoumarins.

$3,3^{\prime}, 3^{\prime}{ }^{\prime}, 3^{\prime}{ }^{\prime}-(($ ethane-1, 2-diylbis (oxy $))$ bis(naphthalene-2,1-diyl))bis(methanetriyl))tetrakis (4-hydroxy-2H-chromen-2-one) (3a): Yield: 72\%. M.p. = 249-251 ${ }^{\circ} \mathrm{C}$. IR $\left(\mathrm{KBr}, \mathrm{cm}^{-1}\right): 3448(\mathrm{O}-\mathrm{H}), 1715(\mathrm{C}=\mathrm{O})$ and 1663 $(\mathrm{C}=\mathrm{C}) .{ }^{1} \mathrm{H}$ NMR (400 MHz, DMSO): $\delta=4.79-4.82$ (br s, 4H, $2 \mathrm{CH}_{2}-\mathrm{O}$ ), 6.05 (br s, 2H, 2CH), 6.93-7.03 (m, 4H, 2CH, H-Ar), 7.27-7.47 (m, 10H, H-Ar), 7.65-7.83 (m, 10H, H-Ar), 8.14 (br s, 2H, H-Ar), 8.75-8.77 (m, 2H, H-Ar), 10.74-10.76 (br s, 4H, 4OH). ${ }^{13} \mathrm{C}$ NMR (100 MHz, DMSO): $\delta=54.75,103.01,115.63$, 116.60, 117.27, 121.81, 123.00, 124.53, 125.56, 126.82, 127.66, $128.43,129.43,131.25,131.96,147.92,152.17,154.05,160.89$, 161.54, 161.99. Anal. Calc. for $\mathrm{C}_{60} \mathrm{H}_{36} \mathrm{O}_{16}$ (982.94): C, 73.32; H, $3.90 \%$. Found: C, 73.38; H, $4.14 \%$.

3,3',3“",3”“-((((oxybis(ethane-2,1-diyl))bis(oxy))bis(3bromo-6,1-phenylene))bis(methane triyl))tetrakis (4-hydroxy-2H-chromen-2-one) (3b): Yield: $77 \%$. M.p. $=375{ }^{\circ} \mathrm{C}$ decomposed. IR (KBr, cm $\left.{ }^{-1}\right): 3448(\mathrm{O}-\mathrm{H}), 1710(\mathrm{C}=\mathrm{O}), 1656$ $(\mathrm{C}=\mathrm{C}) .{ }^{1} \mathrm{H}$ NMR $\left(400 \mathrm{MHz}, \mathrm{DMSO}-\mathrm{d}_{6}\right): \delta=4.06$ (br s, $4 \mathrm{H}$, $2 \mathrm{CH}_{2}-\mathrm{O}$ ), 4.27 (br s, $4 \mathrm{H}, 2 \mathrm{CH}_{2}-\mathrm{O}$ ), 5.64 (s, $\left.2 \mathrm{H}, 2 \mathrm{CH}\right), 6.38$ (s, 2H, H-Ar), 6.70 (d, J = 8.0 Hz, 2H, H-Ar), 7.20-7.25 (m, 8H, H-Ar), 7.47-7.55 (m, 8H, H-Ar), 7.82-7.85 (m, 4H, H-Ar), 12.60-12.61 (br s, 4H, 4OH). ${ }^{13} \mathrm{C}$ NMR (100 MHz, DMSO): $\delta=32.89,65.88,67.35,111.51,112.96,116.33,120.47,123.16$, 127.26, 128.35, 128.45, 132.67, 136.00, 153.47, 156.44, 160.56, 161.89, 163.72. Anal. Calc. for $\mathrm{C}_{54} \mathrm{H}_{36} \mathrm{Br}_{2} \mathrm{O}_{15}$ (1084.66): C, 59.80; H, $3.35 \%$. Found: C, 59.42; H, $3.73 \%$.

$3,3^{\prime}, 3^{\prime \prime}, 3^{\prime \prime}-((($ oxybis (ethane-2,1-diyl)) bis(oxy)) bis(2,1-phenylene))bis(methanetriyl)) tetrakis (4-hydroxy2H-chromen-2-one) (3c): Yield: $79 \%$. M.p. $=233-235{ }^{\circ} \mathrm{C}$. IR $\left(\mathrm{KBr}, \mathrm{cm}^{-1}\right): 3432(\mathrm{O}-\mathrm{H}), 1656(\mathrm{C}=\mathrm{O}), 1610(\mathrm{C}=\mathrm{C}) .{ }^{1} \mathrm{H}$ NMR (400 MHz, DMSO- $\left.\mathrm{d}_{6}\right): \delta=4.02\left(\mathrm{br} \mathrm{s}, 4 \mathrm{H}, 2 \mathrm{CH}_{2}-\mathrm{O}\right), 4.25-4.26$ (m, 4H, 2 $\left.\mathrm{CH}_{2}-\mathrm{O}\right), 5.62$ (s, 2H, 2CH), 6.99-7.24 (m, 16H, H-Ar), 7.47-7.51 (m, 4H, H-Ar), 7.80-7.83 (m, 4H, H-Ar), 12.57 (br s, $2 \mathrm{H}, 4 \mathrm{OH}) .{ }^{13} \mathrm{C}$ NMR (100 MHz, DMSO): $\delta=32.90,65.06$, 67.33, 90.97, 104.12, 111.48, 115.72, 116.31, 118.47, 120.27, 123.46, 123.82, 126.96, 131.36, 132.66, 152.07, 155.76, 164.34, 165.34. Anal. Calc. for $\mathrm{C}_{54} \mathrm{H}_{38} \mathrm{O}_{15}$ (926.87): C, 69.98; H, 4.13 $\%$. Found: C, 69.54; H, $4.58 \%$.

7,7'-((ethane-1,2-diylbis(oxy))bis(3-bromo-6,1-phenylene))bis(6H-pyrano[3,2-c:5,6-c']dichromene-6,8(7H)dione) (3d): Yield: $74 \%$. M.p. $=370{ }^{\circ} \mathrm{C}$ decomposed. $\mathrm{IR}$ $\left(\mathrm{KBr}, \mathrm{cm}^{-1}\right)$ : $1662(\mathrm{C}=\mathrm{O}), 1611(\mathrm{C}=\mathrm{C}) .{ }^{1} \mathrm{H}$ NMR $(400 \mathrm{MHz}$, DMSO-d $\left.)_{6}\right): \delta=3.64\left(\mathrm{~s}, 4 \mathrm{H}, 2 \mathrm{CH}_{2}-\mathrm{O}\right), 6.15(\mathrm{~s}, 2 \mathrm{H}, \mathrm{CH}), 6.25$ (d, J = 8.8 Hz, 2H, H-Ar), 7.04-7.06 (m, 4H, H-Ar), 7.20-7.27 (m, 8H, H-Ar), 7.49 (m, 4H, H-Ar), 7.79-7.81 (m, 4H, H-Ar). ${ }^{13} \mathrm{C}$ NMR (100 MHz, DMSO-d $\left.\mathrm{d}_{6}\right): \delta=33.37,57.90,110.71,115.93$, 117.15, 120.29, 123.45, 124.55, 126.28, 129.48, 131.34, 131.82, 152.78, 164.38, 167.83. Anal. Calc. for $\mathrm{C}_{52} \mathrm{H}_{32} \mathrm{Br}_{2} \mathrm{O}_{14}$ (1001.99): C, 62.17; H, $2.81 \%$. Found: C, 61.32; H, $3.13 \%$. 
7,7'-(((ethane-1,2-diylbis(oxy))bis(ethane-2,1-diyl)) bis(oxy))bis(2,1-phenylene))bis(6H-pyrano[3,2-c:5,6-c'] dichromene-6,8(7H)-dione) (3e): Yield: 82\%. M.p. = 236-239 ${ }^{\circ} \mathrm{C}$. IR $\left(\mathrm{KBr}, \mathrm{cm}^{-1}\right): 1655(\mathrm{C}=0), 1609(\mathrm{C}=\mathrm{C}) .{ }^{1} \mathrm{H}$ NMR (400 MHz, DMSO): $\delta=3.24$ (t, J = 4.6 Hz, 4H, $2 \mathrm{CH}_{2}-\mathrm{O}$ ), 3.84 $\left(\mathrm{t}, \mathrm{J}=4.6 \mathrm{~Hz}, 4 \mathrm{H}, 2 \mathrm{CH}_{2}-\mathrm{O}\right), 4.20\left(\mathrm{t}, \mathrm{J}=4.6 \mathrm{~Hz}, 4 \mathrm{H}, 2 \mathrm{CH}_{2}-\right.$ 0), 6.27 (s, 2H, CH), 6.84-6.90 (m, 4H, H-Ar), $7.12(\mathrm{~d}, \mathrm{~J}=$ $7.6 \mathrm{~Hz}, 2 \mathrm{H}, \mathrm{H}-\mathrm{Ar}$ ), 7.18 (t, J = 7.8 Hz, 2H, H-Ar), 7.33-7.40 (m, 8H, H-Ar), 7.60 (td, J = 7.2 and $1.2 \mathrm{~Hz}, 4 \mathrm{H}, \mathrm{H}-\mathrm{Ar}$ ), 7.92 (dd, J= 6.8 and $1.2 \mathrm{~Hz}, 4 \mathrm{H}, \mathrm{H}-\mathrm{Ar})(\mathrm{s}, 2 \mathrm{H}, 2 \mathrm{OH}) .{ }^{13} \mathrm{C}$ NMR (100 MHz, DMSO): $\delta=32.99,66.94,68.78,69.30,104.91$, $111.48,116.05,116.90,120.04,123.51,123.94,127.29,127.53$, 127.92, 131.95, 151.88, 156.53, 162.90, 164.21. Anal. Calc. for $\mathrm{C}_{56} \mathrm{H}_{42} \mathrm{O}_{16}$ (934.23): C, 71.94; H, $4.10 \%$. Found: C, 71.55; $\mathrm{H}, 4.67 \%$.

7,7'-(((ethane-1,2-diylbis(oxy))bis(ethane-2,1-diyl)) bis(oxy))bis(3-bromo-6,1-phenylene))bis(6H-pyrano[3,2c:5,6-c']dichromene-6,8(7H)-dione) (3f): Yield: $89 \%$. M.p. $=265-267^{\circ} \mathrm{C}$. IR (KBr, cm $\left.{ }^{-1}\right), 1651(\mathrm{C}=\mathrm{O}), 1607(\mathrm{C}=\mathrm{C})$. ${ }^{1} \mathrm{H}$ NMR (400 MHz, DMSO): $\delta=3.0\left(\mathrm{~s}, 4 \mathrm{H}, 2 \mathrm{CH}_{2}-\mathrm{O}\right), 3.30$ (t, J = 4.8 Hz, 4H, $2 \mathrm{CH}_{2}-\mathrm{O}$ ), $3.83\left(\mathrm{t}, \mathrm{J}=4.8 \mathrm{~Hz}, 4 \mathrm{H}, 2 \mathrm{CH}_{2}-\mathrm{O}\right.$ ), 6.19 (s, 2H, CH), 6.83 (d, J = 8.8 Hz, 2H, H-Ar), 7.19 (d, J = $2.0 \mathrm{~Hz}, 2 \mathrm{H}, \mathrm{H}-\mathrm{Ar}$ ), 7.26-7.35 (m, 8H, h-Ar), 7.56 (td, J = 7.8, 1.2 $\mathrm{Hz}, 4 \mathrm{H}, \mathrm{H}-\mathrm{Ar}$ ), 7.99 (dd, J = 7.8, $1.2 \mathrm{~Hz}, 4 \mathrm{H}, \mathrm{H}-\mathrm{Ar}$ ). ${ }^{13} \mathrm{C}$ NMR (100 MHz, DMSO): $\delta=33.64,67.86,69.14,69.90,104.62$, 112.03, 114.11, 116.35, 118.48, 124.00, 124.17, 129.99, 131.14, $132.00,132.48,152.59,156.31,164.27,164.98$. Anal. Calc. for $\mathrm{C}_{56} \mathrm{H}_{36} \mathrm{Br}_{2} \mathrm{O}_{14}$ (1090.05): C, 61.55; H, 3.32\%. Found: C, 60.89; $\mathrm{H}, 3.50 \%$.

\section{Antimicrobial activity}

The antibacterial activity of the heterocyclic compounds (3a-f) against Gram-negative bacterial strains (Pseudomonas aeruginosa (PTCC 1310), Acinetobacter baumannii (PTCC 1855), Shigella dysenteriae (PTCC 1188) and Grampositive bacterial strains (Enterococcus faecalis (PTCC 1778), Streptomyces fradiae (PTCC 1121), Staphylococcus aureus (PTCC 1189) and fungi (Candida albicans (PTCC 5027)) was examined by the disc diffusion technique by utilizing $100 \mu \mathrm{L}$ of suspension possessing $10^{6} \mathrm{CFU} / \mathrm{mL}$ of bacteria, spread on Muller-Hinton agar (MHA) medium [40, 41]. These microorganisms were prepared from the Persian Type Culture Collection (PTCC), Tehran, Iran. Then sterile filter paper discs (6 $\mathrm{mm}$ in diameter) were saturated with $20480 \mu \mathrm{g} / \mathrm{mL}$ of the compounds and were positioned on to Muller-Hinton agar. The plates were incubated for $18-24 \mathrm{~h}$ at $37^{\circ} \mathrm{C}$. After this period, the diameter of the clear inhibition zone (IZD) around the disc was derived and denoted in millimeters as its antibacterial behavior. All the antibiogram assays were replicated a minimum of three times. The findings were documented as the average of three autonomous tests. Control tests were carried out under similar condition by means of standard reference antibiotics (Gentamicin for bacteria and Terbinafine for fungi).

\section{References}

[1] Sekino E, Kumamoto T, Tanaka T, Ikeda T, Ishikawa T. Concise synthesis of anti-HIV-1 active (+)-inophyllum $B$ and (+)-calanolide $A$ by application of (-)-quinine-catalyzed intramolecular oxo-Michael addition. J Org Chem. 2004;69(8):2760-7.

[2] Anand P, Singh B, Singh N. Review on coumarins as acetylcholinesterase inhibitors for Alzheimer's disease. Bioorg Med Chem. 2012;20(3):1175-80.

[3] Souza LG, Rennó MN, Figueroa-Villar JD. Coumarins as cholinesterase inhibitors: A review. Chem Biol Interact. 2016;254:1-23.

[4] Sandhu S, Bansal Y, Silakari O, Bansal G. Coumarin hybrids as novel therapeutic agents. Bioorg Med Chem. 2014;22(15):3806-14.

[5] Karataş MO, Uslu H, Alıcı B, Gökçe B, Gencer N, Arslan O. Some coumarins and benzoxazinones as potent paraoxonase 1 inhibitors. J Enzyme Inhib Med Chem. 2016;31(6):1386-91.

[6] Kaur M, Kohli S, Sandhu S, Bansal Y, Bansal G. Coumarin: A promising scaffold for anticancer agents. Anticancer Agents Med Chem. 2015;15(8):1032-48.

[7] Emami S, Dadashpour S. Current developments of coumarinbased anti-cancer agents in medicinal chemistry. Eur J Med Chem. 2015;102:611-30.

[8] Venugopala KN, Rashmi V, Odhav B. Review on natural coumarin lead compounds for their pharmacological activity. BioMed Res Int. 2013;2013:14.

[9] Ellis GP (Ellis GP, editor). Chromenes, Chromanones, and Chromones. New York: John Wiley and Sons; 1977.

[10] Kostova I. Synthetic and natural coumarins as cytotoxic agents. Curr Med Chem. 2005;5(1):29-46.

[11] Xu J, Kjer J, Sendker J, Wray V, Guan H, Edrada R, et al. Cytosporones, coumarins, and an alkaloid from the endophytic fungus Pestalotiopsis sp. isolated from the Chinese mangrove plant Rhizophora mucronata. Bioorg Med Chem. 2009;17(20):7362-7.

[12] He HP, Shen YM, Zuo GY, Yang XS, Hao XJ. Dinorditerpene, diterpenes, alkaloids, and coumarins from Clausena dunniana. Helv Chim Acta. 2003;86(9):3187-93.

[13] Takakusa H, Kikuchi K, Urano Y, Sakamoto S, Yamaguchi K, Nagano T. Design and synthesis of an enzyme-cleavable sensor molecule for phosphodiesterase activity based on fluorescence resonance energy transfer. J Am Chem Soc. 2002;124(8):1653-7.

[14] Sohrab MH, Hasan CM, Rashid MA, Lunamarin C. A new terpenoid coumarin from Clausena heptaphylla. Pharmazie. 2002;57(8):573-4.

[15] Kwak JH, Lee KB, Schmitz FJ. Four new coumarin derivatives from artemisia k eiskeana. J Nat Prod. 2001;64(8):108-83. 
[16] Schuster N, Christiansen C, Jakupovic J, Mungai M. An unusual [2+2] cycloadduct of terpenoid coumarin from Ethulia vernonioides. Phytochemistry. 1993;34(4):1179-81.

[17] Bestmann HJ, Kern F, Schäfer D, Witschel MC. 3, 4-Dihydroisocoumarins, a new class of ant trail pheromones. Angew Chem Int Ed Engl. 1992;31(6):795-6.

[18] Wang KP, Lei Y, Chen JP, Ge ZH, Liu W, Zhang Q, et al. The coumarin conjugate: synthesis, photophysical properties and the ratiometric fluorescence response to water content of organic solvent. Dyes Pigm. 2018;151:233-7.

[19] Bayraktutan T, Onganer Y. Spectral-luminescent study of coumarin 35 as fluorescent "light-up" probe for BSA and DNA monitoring. Dyes Pigm. 2017;142:62-8.

[20] Teixeira E, Lima JC, Parola AJ, Branco PS. Incorporation of coumarin-based fluorescent monomers into co-oligomeric molecules. Polymers (Basel). 2018;10(4):396-406.

[21] Jadhav MM, Vaghasiya JV, Patil DS, Soni SS, Sekar N. Structureefficiency relationship of newly synthesized 4-substituted donor- $\pi$-acceptor coumarins for dye-sensitized solar cells. New J Chem. 2018;42(7):5267-75.

[22] Gandioso A, Bresolí-Obach R, Nin-Hill A, Bosch M, Palau M, Galindo A, et al. Redesigning the coumarin scaffold into small bright fluorophores with far-red to near-infrared emission and large stokes shifts useful for cell imaging. J Org Chem. 2018;83(3):1185-95.

[23] Ye FF, Gao JR, Sheng WJ, Jia JH. One-pot synthesis of coumarin derivatives. Dyes Pigm. 2008;77(3):556-8.

[24] Jagtap AR, Satam VS, Rajule RN, Kanetkar VR. The synthesis and characterization of novel coumarin dyes derived from 1 , 4-diethyl-1, 2, 3, 4-tetrahydro-7-hydroxyquinoxalin-6-carboxaldehyde. Dyes Pigm. 2009;82(1):84-9.

[25] Appendino G, Cravotto G, Tagliapietra S, Ferraro S, Nano GM, Palmisano $G$. The chemistry of coumarin derivatives. Part 3. Synthesis of 3-alkyl-4-hydroxycoumarins by reductive fragmentation of 3, 3'-alkyiidene-4, 4'-dihydroxybis [coumarins]. Helv Chim Acta. 1991;74(7):1451-8.

[26] Manolov I, Maichle-Moessmer C, Danchev N. Synthesis, structure, toxicological and pharmacological investigations of 4-hydroxycoumarin derivatives. Eur J Med Chem. 2006;41(7):882-90.

[27] Khurana JM, Kumar S. Tetrabutylammonium bromide (TBAB): a neutral and efficient catalyst for the synthesis of biscoumarin and 3, 4-dihydropyrano [c] chromene derivatives in water and solvent-free conditions. Tetrahedron Lett. 2009;50(28):4125-7.

[28] Liu J, Feng Z, Xu J, Wang Y, Zhang P. Rare biscoumarins and a chlorogenic acid derivative from Erycibe obtusifolia. Phytochemistry. 2007;68(13):1775-80.

[29] Park BY, Min BS, Oh SR, Kim JH, Bae KH, Lee HK. Isolation of flavonoids, a biscoumarin and an amide from the flower buds of Daphne genkwa and the evaluation of their anti-complement activity. Phytother Res. 2006;20(7):610-3.

[30] Khan KM, Iqbal S, Lodhi MA, Maharvi GM, Choudhary MI, Perveen S. Biscoumarin: new class of urease inhibitors; economical synthesis and activity. Bioorg Med Chem. 2004;12(8):1963-8.

[31] Lehmann J. Thrombosis. Treatment and prevention with methylene-bis-(hydroxycoumarin). Lancet. 1943;244:611-3.

[32] Kostova I, Manolov I, Nicolova I, Konstantinov S, Karaivanova M. New lanthanide complexes of 4-methyl-7-hydroxycoumarin and their pharmacological activity. Eur J Med Chem. 2001;36(4):339-47.

[33] Schulman S, Lindmarker P. Incidence of cancer after prophylaxis with warfarin against recurrent venous thromboembolism. N Engl J Med. 2000;342:1953-8.

[34] Madari H, Panda D, Wilson L, Jacobs RS. Dicoumarol: a unique microtubule stabilizing natural product that is synergistic with Taxol. Cancer Res. 2003;63(6):1214-20.

[35] Cravotto G, Nano GM, Palmisano G, Tagliapietra S. The reactivity of 4-hydroxycoumarin under heterogeneous high-intensity sonochemical conditions. Synthesis. 2003;8:1286-91.

[36] Hurenkamp JH, Browne WR, Augulis R, Pugžlys A, Loosdrecht $\mathrm{PH}$, Esch JH, et al. Intramolecular energy transfer in a tetra-coumarin perylene system: influence of solvent and bridging unit on electronic properties. Org Biomol Chem. 2007;5(20):3354-62.

[37] Chiang CC, Mouscadet JF, Tsai HJ, Liu CT, Hsu LY. Synthesis and HIV-1 integrase inhibition of novel bis-or tetra-coumarin analogues. Chem Pharm Bull (Tokyo). 2007;55(12):1740-3.

[38] Esenpınar AA, Bulut M. Synthesis and characterization of novel $\alpha$-or $\beta$-tetra [6, 7-dihexyloxy-3-(4-oxyphenyl) coumarin]substituted metal-free and metallo phthalocyanines. Polyhedron. 2009;28(14):3129-37.

[39] Köksoy MA, Köksoy B, Durmuş M, Bulut M. Preparation, characterization and photophysicochemical properties of novel tetra 7-(diethyl 2-methylmalonatoxy)-3-(p-oxyphenyl) coumarinsubstituted zinc (II) and indium (III) chloride phthalocyanines. J Organomet Chem. 2016;822:125-34.

[40] Can OS, Kuş A, Kaya EN, Durmuş M, Bulut M. Synthesis and characterization of 6, 8-di-tert-butyl-3-[p-(propynyl) phenoxy] coumarin substituted phthalocyanines and investigation of their photophysical and photochemical properties. Inorg Chim Acta. 2017;465:31-7.

[41] Faryabi M, Sheikhhosseini E. Efficient synthesis of novel benzylidene barbituric and thiobarbituric acid derivatives containing ethyleneglycol spacers. J Iran Chem Soc. 2015;12:427-32.

[42] Sheikhhosseini E, Soltaninejad S. Design and efficient synthesis of novel biological benzylidenemalononitrile derivatives containing ethylene ether spacers. Iran J Sci Technol Trans Sci. 2018;43:1-7.

[43] Tavakoli-Hoseini N, Heravi MM, Bamoharram FF, Davoodnia A, Ghassemzadeh M. An unexpected tetracyclic product isolated during the synthesis of biscoumarins catalyzed by $\left[\mathrm{MIM}\left(\mathrm{CH}_{2}\right)_{4} \mathrm{SO}_{3} \mathrm{H}\right]\left[\mathrm{HSO}_{4}\right]$ : characterization and X-ray crystal structure of 7-(2-hydroxy-4-0xo-4H-chromen-3-yl)-6H,7Hchromeno[4,3-b]chromen-6-one. J Mol Liq. 2011; 163(3):122-7.

[44] Rezaei R, Moezzi F, Doroodmand MM. Propane-1,2,3-triyl tris(hydrogen sulfate): A mild and efficient recyclable catalyst for the synthesis of biscoumarin derivatives in water and solvent-free conditions. Chin Chem Lett. 2014;25(1):183-6.

[45] Şahin F, Karaman I, Güllüce M, Öğütçü H, Şengül M, Adıgüzel A, et al. Evaluation of antimicrobial activities of Satureja hortensis L. J Ethnopharmacol. 2003;87(1):61-5.

[46] Cosentino S, Tuberoso Cl, Pisano B, Satta ML, Mascia V, Arzedi E, et al. In-vitro antimicrobial activity and chemical composition of Sardinian thymus essential oils. Lett Appl Microbiol. 1999;29(2):130-5. 